\title{
Type studies in Clitocybe. 2.
}

\author{
Harri Harmaja
}

Botanical Museum, University of Helsinki, SF-00170 Helsinki, Finland

\begin{abstract}
HARMAJA, H. 1976: Type studies in Clitocybe. 2. - Karstenia 15:16-18.
The holotypes of seven taxa, described under the generic name Clitocybe (Fr.) Staude (Agaricales) or considered as belonging to that genus, are scrutinized. All but one turned out to be referable to genera other than Clitocybe. Four of them are considered to be synonymous with other species of those genera while two are found valid. For the lastnamed species the following new combinations are therefore made: Calocybe aromatica (Murr.) Harmaja and Lyophyllum subnitens (Bigelow) Harmaja. In addition, the new combination Clitocybe dryadicola (Favre) Harmaja is made. Moreover, to the contrary of the author's previous opinion, Agaricus clitocyboides Cooke \& Massee is considered distinct from Singerella (Clitocybe) hydrogramma (Fr.) Harmaja and the resulting new combination is made: Singerella clitocyboides (Cooke \& Massee) Harmaja. Notes on Pseudoclitocybe (Clitocybe) atra (Vel.) Harmaja are also presented. In addition, the carminophilic (siderophilic) granules, or vesicles connected with the endoplasmatic reticulum, of the basidia of Lyophyllum have been observed to be cyanophilic, too, a response not reported before.
\end{abstract}

Melanoleuca aromatica Murrill, North American Fl. 10: 15. 1914. - Tricholoma aromaticum (Murr.) Sacc. \& Trott., Syll. Fung. 23: 32. 1925. - Clitocybe aromatica (Murr.) Bigelow, Lloydia 28: 161. 1965. - Holotype (part) examined: U.S.A., Michigan, Washtenaw Co., Ann Arbor, Cascade Glen, 1907-1011, leg. C.H. Kauffman (MICH). - I found the spore wall moderately cyanophilic except for the cyanophobic hilar appendix. The wall is also weakly to moderately carminophilic. After soaking a piece of gill in $5 \% \mathrm{KOH}$ for some time, the nuclei of the spores stained with acetocarmine, and their number was observed to be one per spore. In the lastnamed stain the basidia contained siderophilic (carminophilic) granules, which are now known as 'ER vesicles' (vesicles connected with the endoplasmatic reticulum). The above characters, together with the macroscopic and microscopic features mentioned in the original description, show the type to belong to the genus Calocybe Kühn. ex Donk. The specimen represents a valid species taxonomi- cally very close to C. gambosa (Fr.) Donk, from which it differs throught the slightly darker colours of the fruit body, the most probably slightly dextrinoid walls of the hyphae of gill trama, the slightly smaller (especially narrower) spores, and fruiting in autumn, in September and October. My conclusion: Melanoleuca aromatica is a valid species of the genus Calocybe, for which reason the following appropriate new combination is made: Calocybe aromatica (Murr.) Harmaja, n. comb. (Melanoleuca aromatica Murrill, North American Fl. 10: 15. 1914).

Clitocybe atra Vel. - Pseudoclitocybe atra (Vel.) Harmaja (see HARMAJA 1974c). Three additional notes, not mentioned in HARMAJA $1974 \mathrm{c}$, on the diagnostic characters of this species are presented here. (1) The pure brown colour of the basidiocarp (which thus lacks any grayish tint) was emphasized as a diagnostic character of the species in that paper of mine, especially when $P$. atra is compared with $P$. cyathiformis (Fr.) Sing. which possesses rather similar 
spores. The comparison should be made between dried fruit bodies as the fresh ones of all species of the genus Pseudoclitocybe (Sing.) Sing. display brown colours (as do, on the other side, also those dried for several decades ago). (2) The stipe of $P$. atra is rather short, especially in proportion to the diameter of the pileus, which feature, too, possesses most importance in the separation of the species from $P$. cyathiformis. (3) The stipe is, on the average, somewhat more slender than that of $P$. cyathiformis.

Agaricus clitocyboides Cooke \& Massee Clitocybe clitocyboides (Cooke \& Massee) Pegler. - In a previous paper, on studying the holotype, I reduced this species to the synonymy of Singerella (Clitocybe) hydrogramma (Fr.) Harmaja (HARMAJA 1974b). Because of the following two facts I now consider the species distinct from $S$. hydrogramma, at least for the time being: (1) the intercalary dermatochrysocystidia are absent from the stipe cortex, (2) both the specimens of this kind originate from the southern hemisphere (see HARMAJA 1974b). My conclusion: Agaricus clitocyboides is a valid species of the genus Singerella, for which reason the following necessary new combination is made: Singerella clitocyboides (Cooke \& Massee) Harmaja (Agaricus clitocyboides Cooke \& Massee, Grevillea 15: 98. 1887). - I have been told that the generic name Singerella Harmaja (HARMAJA 1974b) should apparently be considered as a later homonym of the older Singeriella Petrak (Pyrenomycetes). However, a difference of one letter between names of unrelated genera is enough for considering such names different and legitimate (International Code of Botanical Nomenclature, Art. 75).

Clitocybe crispa Bigelow \& Smith, Michigan Bot. 5: 224. 1966. - Holotype (part) examined: U.S.A., Michigan, Washtenaw Co., Pinckney State Recreation Area, 1961-09-17, leg. A.H. Smith 64342 (MICH). - The spore wall is weakly cyanophilic and weakly to moderately carminophilic. In acetocarmine the basidia contain siderophilic (carminophilic) granules, or, in other words, the ER vesicles of the basidia are carminophilic. These ER vesicles were also found to be \pm strongly cyanophilic in heated cotton blue, a response never reported before in the literature about the carminophilic basidial granules of any fungus. The characters observed by me together with the macroscopic and microscopic features mentioned in the original description, show the type specimen to belong to the genus Lyophyllum Karst. The species is L. subnitens (Bigelow) Harmaja (see below). My conclusion: Clitocybe crispa is a synonym of Lyophyllum subnitens.

Clitocybe media Peck, Rep. New York State Mus. 42: 114. 1889. - Holotype examined: "Clitocybe media Pk. / North Elba / Chas H. Peck Sept. / Edible." (NYS). - The type represents both macroscopically and microscopically a typical Hygrophorus camarophyllus (Fr.) Fr. The spore wall was found cyanophobic. My determination of the type specimen is distinctly at variance with BIGELOW's (1965) opinion according to which the specimen represents Clitocybe clavipes (Fr.) $\mathrm{Kumm}$. and C. media is consequently a synonym of that species. My conclusion: Clitocybe media is a synonym of Hygrophorus camarophyllus.

Clitocybe pseudoirina Bigelow \& Smith, Brittonia 21: 165. 1969. - Holotype (part) examined: U.S.A., Michigan, Washtenaw Co., Nov. 1964, leg. A.H. Smith 71356 (MICH). The specimen represents in all respects a typical European Lepista irina (Fr.) Bigelow as I already supposed in a previous paper (HARMAJA 1974a) which may be consulted for more detailed comments on this case. My conclusion: Clitocybe pseudoirina is a synonym of Lepista irina.

Clitocybe rivulosa (Fr.) Kumm. var. dryadicola Favre, Ergebn. wiss. Unters. schweizerischen Nationalp. 5: 33: 199. 1955. - Clitocybe candicans (Fr.) Kumm. var. dryadicola (Favre) Lamoure, Bull. Soc. Mycol. France 81: 507. 1965. - Specimen no. 48a in CHUR is herewith selected as the lectotype of Favre's variety. My conclusion: Clitocybe rivulosa var. dryadicola represents a valid species of the genus Clitocybe sensu meo (this case will be treated more comprehensively later), for which reason the following new combination is made: Clitocybe dryadicola (Favre) Harmaja, n. comb. (Clitocybe rivulosa var. dryadicola Favre, Ergebn. wiss. Unters. schweizerischen Nationalp. 5: 33: 199. 1955.)

Clitocybe subnitens Bigelow, Mycologia 50: 50. 1958. - Holotype (part) examined: U.S.A., Michigan, Emmet Co., Wilderness Park, 1953-08-30, leg. H.E. Bigelow 1468 $(\mathrm{MICH})$. Also part of a paratype (A. H. Smith 43462; MICH) studied. This species shares the 
generic and specific characters of $C$. crispa Bigelow \& Smith 1966 (see above). My conclusion: Clitocybe subnitens is a valid species of the genus Lyophyllum Karst., for which reason the following new combination is made: Lyophyllum subnitens (Bigelow) Harmaja, n. comb. (Clitocybe subnitens Bigelow, Mycologia 50: 50. 1958.)

Clitocybe Vasilievae Singer, Ann. Mycol. 41: 26. 1943. - Holotype examined: "Clitocybe Vasilievae Sing. / In steppis prope silvam laricinam / inter Gramineas, $1750 \mathrm{~m}$ / Aktura Tchuyskiye Alpy / Oyrotiya (the last two lines originally in Russian) / 4-VIII-37 Leg. Singer et Vasilieva / 2-IV-38 Det. Singer" (LE). - The spore wall was observed to be inamyloid, indextrinoid, moderately to strongly cyanophilic and weakly to moderately carminophilic. The hilar appendix is, however, cyanophobic. The ER vesicles of the basidia are carminophilic when the basidia are mounted in heated acetocarmine together with rich supply of iron ions. In that stain the nuclei of some spores stained to some extent, and it was found that the spores contained one central nucleus each. The above characters, together with the macroscopic and microscopic features mentioned in the original description, show that it concerns a specimen which is referable to the genus Calocybe Kühn. ex Donk. As for species, the type specimen represents $C$. gambosa (Fr.) Donk. There are, however, some points to be noted. Firstly, the lamellae are apparently somewhat less sinuate than usually in $C$. gambosa. Secondly, the farinaceous odour, so typical of C. gambosa, was not mentioned in the original description; this apparent discrepancy may, however, simply be due to faulty observation. Thirdly, the type specimen was collected on August 4 which is rather late for C. gambosa, but this may be explained by the situation of the collecting site high on the mountains. At present it is impossible to judge whether the above mentioned apparent discrepancies are true or not, and, in the former case, whether they justify the recognition of Clitocybe vasilievae as a species distinct from Calocybe gambosa. My conclusion, for the time being, is: Clitocybe vasilievae is a synonym of Calocybe gambosa.

Acknowledgements. - I am indebted to Dr. John H. Haines, Albany (NYS), Dr. Robert L. Shaffer, Ann Arbor (MICH), Dr. J. P. Müller, Chur (CHUR) and Prof. Boris M. Tomilin, Leningrad (LE), for providing type specimens for my studies.

\section{REFERENCES}

BIGELOW, H. E. 1965: The Genus Clitocybe in North America: Section Clitocybe. - Lloydia 28: 139-180.

HARMAJA, H. 1974a: A revision of the generic limit between Clitocybe and Lepista. - Karstenia 14: 82-92.

- 1974b: Singerella n. gen., a separate genus for Clitocybe hydrogramma. - Karstenia 14: 113-115.

- 1974c: Pseudoclitocybe atra (Vel.) n. comb. - Karstenia 14: 126-128. 